\title{
From computation to biophysics: functional theory of adaptive
} neural excitability

\section{Timm Lochmann*, Boris Gutkin and Sophie Denève}

\author{
Address: Group for Neural Theory, Ecole Normale Supérieure, Pairs, France \\ Email: Timm Lochmann* - timm.lochmann@ens.fr \\ * Corresponding author
}

from Eighteenth Annual Computational Neuroscience Meeting: CNS*2009

Berlin, Germany. 18-23 July 2009

Published: 13 July 2009

BMC Neuroscience 2009, I0(Suppl I):P98 doi:I0.I I86/I47I-2202-I0-SI-P98

This abstract is available from: http://www.biomedcentral.com/I47I-2202/I0/SI/P98

(C) 2009 Lochmann et al; licensee BioMed Central Ltd.

Realistic sensory stimulation results in synaptic inputs that appear to be noisy and vary rapidly over time. To extract the stimulus-dependent information contained in such input streams, cells would have to integrate inputs both over time and over the different synaptic afferents. How individual neurons actually respond to such input depends not only on its statistics, but also on various intrinsic voltage- and spike-dependent processes defining neuronal excitability. While the dynamical aspects of the underlying biophysical mechanisms have been studied in great detail, their functional implications at the single cell level are still not understood completely.

Starting from a functional approach, we (1) examine generic dynamical properties of sensory neurons that would allow them to efficiently extract and signal information from their inputs and (2) ask how these properties might be realized by the biophysics of the neuron. More specifically, we build upon a theory describing the dynamics of spiking neural units that optimally integrate synaptic input [1]. Using principles of Bayesian inference, the theory specifies how to infer the probabilities of specific events from the noisy synaptic input they cause. We show that for the following regimes, optimal inference can be described by mechanisms known from biophysical models. (a) When strongly inhibited, processing is dominated by rectifying forces, like voltage-dependent depolarizing currents, preventing the membrane potential to become too hyperpolarized. (b) In an intermediate regime, input is integrated linearly with a leak current adjusting the time constant of integration. (c) For strong excitatory stimulation, the process acts as a coincidence detector with spike-based adaptation increasing the membrane conductance after each output spike. Each of these regimes can be associated with different families of voltage dependent channels: hyperpolarization activated depolarizing currents $\left(I_{h}\right)$, voltage independent leak currents, and sources of spike-dependent adaptation $\left(\mathrm{Ca}^{2+}\right.$ controlled K-currents).

We demonstrate that a biophysically motivated model including such components can closely match the optimal computational model regarding both input/output rate function and information transmitted per spike. Blocking $I_{h}$ and $\mathrm{Ca}^{2+}$ results in a simple leaky integrate and fire model with severely degraded inference, delayed response to stimulus onsets, and impaired detection of short stimuli.

Our approach tightly links biophysical parameters (e.g., integration timescale) to expected input statistics (e.g., how quickly stimulation changes). This makes predictions about how specific dynamical aspects contribute to the information transmitted and might help to understand how natural neuromodulators or pharmacological substances acting on the corresponding channels affect sensory integration. 


\section{References}

I. Denève S: Bayesian spiking neurons I: inference. Neural Computation 2007, 20:91-II7.

Publish with Bio Med Central and every scientist can read your work free of charge

"BioMed Central will be the most significant development for disseminating the results of biomedical research in our lifetime. " Sir Paul Nurse, Cancer Research UK

Your research papers will be:

- available free of charge to the entire biomedical community

- peer reviewed and published immediately upon acceptance

- cited in PubMed and archived on PubMed Central

- yours - you keep the copyright

Submit your manuscript here:

http://www.biomedcentral.com/info/publishing_adv.asp 